\title{
Opa binding to cellular CD66 receptors mediates the transcellular traversal of Neisseria gonorrhoeae across polarized T84 epithelial cell monolayers
}

Jun Wang, ${ }^{1,2}$ Scott D. Gray-Owen, ${ }^{1}$ Alexander Knorre, ${ }^{1 \dagger}$ Thomas F. Meyer ${ }^{1,2 *}$ and Christoph Dehio ${ }^{1}$

${ }^{1}$ Max-Planck-Institut für Biologie, Abteilung

Infektionsbiologie, Spemannstraße 34, D-72076

Tübingen, Germany.

${ }^{2}$ Max-Planck-Institut für Infektionsbiologie, Abteilung

Molekulare Biologie, Monbijoustraße 2, D-10117 Berlin, Germany.

\section{Summary}

We have analysed the capacity of the 11 phase-variable, opacity-associated (Opa) proteins encoded by Neisseria gonorrhoeae MS11 to mediate traversal across polarized monolayers of the human colonic carcinoma T84 cell line. Gonococci expressing either the heparan sulphate proteoglycan (HSPG) binding Opa protein $\left(\mathrm{Opa}_{50}\right)$ or no Opa protein $\left(\mathrm{Opa}^{-}\right)$did not interact with the apical pole of T84 monolayers, whereas the 10 variant Opa proteins previously shown to bind CD66 receptors were found to mediate efficient gonococcal adherence and transepithelial traversal. Consistent with this, T84 cells were shown by reverse transcriptase-polymerase chain reaction (RT-PCR) and immunoblotting to co-express CD66a (BGP), CD66c (NCA) and CD66e (CEA). The recruitment of $\mathrm{CD} 66$ receptors by Opa-expressing gonococci indicates their involvement in mediating adherence to the surface of T84 cells, and these bacterial interactions could be inhibited completely using polyclonal antibodies cross-reacting with all of the CD66 proteins co-expressed on T84 cells. Consistent results were obtained when Opa proteins were expressed in Escherichia coli, suggesting that the Opa-CD66 interaction is sufficient to mediate bacterial traversal. Transcytosis of Opa-expressing $\boldsymbol{N}$. gonorrhoeae or $E$. coli did not disrupt the barrier function of infected monolayers, as indicated by a sustained transepithelial electrical resistance (TEER) throughout the course of infection, and confocal laser scanning and electron

Received 10 April, 1997; revised 1 August, 1997; accepted 5 August, 1997. †Present address: Klinik für Tumorbiologie, Institut für Experimentelle Krebsforschung, D-79106 Freiburg, Germany. *For correspondence in Tübingen. E-mail sinfbio@mpib-tuebingen.mpg.de; Tel. (7071) 601 221; Fax (7071) 610379. microscopy both suggest a transcellular rather than a paracellular route of traversal across the monolayers. Parallels between the results seen here and previous work done with organ cultures confirm that T84 monolayers provide a valid model for studying neisserial interactions with the mucosal surface, and suggest that $\mathrm{CD} 66$ receptors contribute to this process in vivo.

\section{Introduction}

Neisseria gonorrhoeae, the aetiological agent of gonorrhoea, is a strictly human pathogen, and no animal model of gonococcal infection is yet available. Because of this, the precise mechanism of interaction between $N$. gonorrhoeae and mucosal tissues is still not fully appreciated. Previous reports have yielded morphological descriptions of the initial stages of infection on various epithelial cell lines cultured in vitro (van Putten and Duensing, 1997). Pili play a central role in localized neisserial infection by mediating the selective primary adherence to secretory (non-ciliated) epithelial cells (McGee et al., 1981; Mosleh et al., 1997) and possess additional binding functions, which may contribute to gonococcal colonization of mucosal surfaces (Rudel et al., 1992). After pilus-mediated events, the gonococci obtain a secondary tight contact with epithelial surfaces via the phase-variable, colony opacity-associated (Opa) proteins. One of these variants, Opa ${ }_{50}$, mediates adherence to, and invasion into, cultured epithelial cells via binding to heparan sulphate-containing proteoglycan (HSPG) receptors (Chen et al., 1995; van Putten and Paul, 1995) and the extracellular matrix proteins vitronectin (Vn) (Duensing and van Putten, 1997; Gomez-Duarte et al., 1997; Dehio et al., 1998) and fibronectin (van Putten et al., 1998). Recently, members of the CD66 family, CD66a (biliary glycoprotein; BGP), CD66c (non-specific crossreacting antigen; NCA) and CD66d (CEA gene family member 1; CGM1) have been identified as receptors for the other Opa protein variants, which mediate neisserial interactions with polymorphonuclear neutrophils (PMNs; Chen and Gotschlich, 1996; Virji et al., 1996; Gray-Owen et al., 1997a). CD66b (CEA gene family member 6; CGM6) is also expressed on PMNs, but it is not bound by any of the $11 \mathrm{~N}$. gonorrhoeae MS11 Opa protein variants (Bos et al., 1997; Chen et al., 1997; Gray-Owen et al., 1997a, b). Individual members of the CD66 family 
are also distributed differentially on various other tissue types (Berling et al., 1990; Thompson et al., 1991; Majuri et al., 1994). Virji et al. (1996) have shown that CD66a expressed on non-polarized HT29 colonic carcinoma and A549 lung carcinoma cell lines can mediate the binding and invasion of meningococci in vitro. The gonococcal Opa variants also mediate adherence to, and invasion into, stably transfected HeLa cell lines expressing individual CD66 receptors, including CD66e (carcinoembryonic antigen; CEA; Bos et al., 1997; Chen et al., 1997; GrayOwen et al., 1997a,b), a related protein that is absent from granulocytes but is expressed on certain epithelial and endothelial tissues (Majuri et al., 1994; Prall et al., 1996). Although 10 different Opa proteins bind to CD66 receptors, differential specificities do exist (Bos et al., 1997; Chen et al., 1997; Gray-Owen et al., 1997b), thus implying that they may mediate distinct cellular responses depending on the pattern of CD66 proteins that are expressed. This is consistent with the fact that an enhanced oxidative burst in granulocytic cells is triggered by all Opa proteins that bind CD66a (Gray-Owen et al., 1997b).

The conventional semi-confluent growth of epithelial cells in standard culture dishes does not mimic the polarized arrangement of mucosal cells that exists in situ. The differential expression of certain receptor proteins, including the syndecan receptors (Carey, 1997) that are recognized by gonococcal Opa 50 (van Putten and Paul, 1995), on the apical and basolateral surfaces of polarized cells does make such considerations critical for understanding the biological relevance of receptor interactions during infection. Previously, neisserial infection of fallopian tube organ cultures (FTOCs; McGee et al., 1981), nasopharyngeal organ cultures (NPOCs; Stephens et al., 1983), and primary epithelial cell cultures (Boxberger et al., 1994; Mosleh et al., 1997) have been used to represent better the cellular architecture of the mucosa that exists in vivo. These techniques do, however, require a source of donor tissues, and the in vitro manipulation of such cell cultures and tissues is difficult. Recently, polarized monolayers of the T84 cell line were used to study the effect of neisserial pilus expression on cellular binding and traversal across the epithelium (Merz et al., 1996; Pujol et al., 1997). These cells are derived from a lung metastasis of a human colonic carcinoma and can form polarized monolayers with a robust barrier function when grown on a filter support that allows them to feed from the basolateral surface (Murakami and Masui, 1980; McRoberts and Barrett, 1989; Dharmsathaphorn and Madara, 1990). Under these conditions, T84 cells can form tight junctions, generate numerous microvilli on their apical surface and generally show structural similarity to epithelial cells seen in vivo (Dharmsathaphorn and Madara, 1990). The T84 model system provides a valuable tool for studying primary events that occur during colonization, including the potential effects of polarized receptor distribution and cellular architecture on bacterial binding and intracellular trafficking following phagocytosis. Because of this, T84 cells have been used previously in the study of polymorphonuclear cell (PMN) migration across epithelial monolayers stimulated by Salmonella (McCormick et al., 1993; 1995) and Shigella (Perdomo et al., 1994), as well as for the analysis of adherence to, invasion into and transcytosis across epithelial monolayers by Helicobacter pylori (Corthesy-Theulaz et al., 1996) and pathogenic E. coli (EAEC, EPEC and EHEC; Winsor et al., 1992; Gabastou et al., 1995; Nataro et al., 1996; Philpott et al., 1996). The use of a colon-derived cell line as a model system for gonococcal infection is also justified because anorectal colonization is seen in approximately $40 \%$ of infected women and homosexual men (Handsfield, 1990).

In this study, we have analysed the capacity of distinct gonococcal Opa proteins to mediate bacterial traversal across the polarized T84 epithelial cell monolayer. A cellular basis for the observed transcytotic process was characterized with respect to the contribution of both previously defined host cell receptors and ultrastructural events. We demonstrate that the specific interaction of distinct Opa proteins with their cellular CD66 receptors leads to major rearrangements of the apical cell surface, resulting in tight bacterial adherence and, subsequently, in the transcellular passage of bacteria across the infected monolayer. Opamediated binding to CD66 receptors is itself sufficient to mediate these events, as $E$. coli strains expressing recombinant neisserial Opa proteins also transmigrate to the basolateral surface. The Opa/CD66-mediated cellular binding has been shown previously to mediate interactions between the pathogenic Neisseria and granulocytic cells (Chen and Gotschlich, 1996; Virji et al., 1996; Gray-Owen et al., 1997), epithelial cells lines (Virji et al., 1996; Chen et al., 1997) and with activated primary endothelium (Gray-Owen et al., 1997b). The data presented here suggest that CD66 receptors may also provide a means for the pathogen to achieve the submucosal colonization typical of localized gonococcal infection (McGee et al., 1981), and which may subsequently lead to disseminated gonococcal disease.

\section{Results}

CD66-specific Opa proteins mediate bacterial traversal across polarized T84 monolayers

Previously, Kupsch et al. (1993) generated a series of 11 isogenic $N$. gonorrhoeae and E. coli strains, which express individual recombinant Opa proteins cloned from the gonococcal strain MS11. The cloned opa genes were expressed in an MS11 derivative strain N279, which is non-piliated and contains a chromosomal deletion in the HSPG receptorassociated $\mathrm{opaC}_{30}$ locus. To assess the role of pilus, the MS11 derivative N280, which is piliated and also contains a chromosomal deletion in the $\mathrm{opaC}_{30}$ locus, was used to

\footnotetext{
(C) 1998 Blackwell Science Ltd, Molecular Microbiology, 30, 657-671
} 
express individual recombinant Opa proteins. Using these strains, we have analysed the influence of distinct Opa protein variants on bacterial interactions with the apical surface of polarized T84 monolayers. Monolayers were grown on polycarbonate filters with a pore size of $3 \mu \mathrm{m}$ held in a Transwell filter support. In order to ensure that the monolayer's barrier function was intact, only those monolayers that showed a transepithelial electrical resistance (TEER) of more than $700 \Omega \mathrm{cm}^{2}$ at the beginning and end of the experiment were used. Our early experiments indicated that, when the starting concentration of gonococci in the apical reservoir was greater than $4 \times$ $10^{7}$ bacteria $\mathrm{ml}^{-1}$ or that of E. coli was over $2 \times 10^{7}$ bacteria $\mathrm{ml}^{-1}$, a marked decrease in the TEER of T84 monolayers would occur as early as 4-8h after infection (data not shown). Similarly, when the interval between exchanging medium was more than $4 \mathrm{~h}$ for gonococcal infections or $2 \mathrm{~h}$ with E. coli, a decline in TEER was apparent. No correlation existed between epithelial barrier function as measured by TEER and neisserial traversal of the monolayers. We therefore routinely replaced half of the culture medium in the upper and all of the culture medium in the lower reservoirs at 4-h intervals for gonococci and 2-h intervals for $E$. coli throughout all infections. This prevented overgrowth by the bacteria and the accumulation of toxic bacterial products such as lipopolysaccharide (LPS), which could damage the monolayers. Using these conditions, the barrier function of polarized T84 remained intact throughout the infection.

In order to ascertain the level of gonococcal adherence to the apical surface of polarized T84 cells, monolayers were fixed after $4 \mathrm{~h}$ of infection and stained immunocytochemically for bacteria (red) and F-actin (green) and were then analysed by confocal laser scanning microscopy (Fig. 1). Only a few Opa $_{50}$-expressing gonococci (Fig. 1A) or non-opaque $\left(\mathrm{Opa}^{-}\right.$) gonococci (data not shown) were associated with the monolayer, while a high density of each of the remaining 10 Opa proteins $\left(\mathrm{Opa}_{51-60}\right.$; as a representative, see $\mathrm{Opa}_{52}$ in Fig. 1B) were found to adhere. As shown previously by Merz et al. (1996), piliated gonococci also adhered to T84 cells (Fig. 1C), typically existing as larger clusters than Opa-expressing bacteria.

The microscopic analysis of infected samples suggested that gonococci that express Opa proteins specific for CD66 were engulfed by T84 cells. To determine whether adherent bacteria could traverse across the polarized monolayer, the number of viable bacteria present within the lower, basolateral reservoir was determined at various time points after infection of the apical surface. The filters were also moved to fresh basolateral medium at each time point in order to reduce the contribution of bacterial growth to observed changes in bacterial density. Consistent with the fact that they do not interact with the apical surface (Fig. 1A), no significant levels of either $\mathrm{Opa}^{-}$- or Opa ${ }_{50^{-}}$ expressing gonococci were found in the basolateral reservoir even after $24 \mathrm{~h}$ (Fig. 2A). Expression of any one of the other 10 gonococcal Opa proteins (i.e. Opa ${ }_{51}-\mathrm{Opa}_{60}$ ) did, however, result in the appearance of bacteria in the lower reservoir, thus indicating that these variants can mediate efficient transmigration across T84 monolayers. The lack of transmigration by an isogenic gonococcal strain expressing $\mathrm{Opa}_{30}$, the chromosomally expressed homologue of $\mathrm{Opa}_{50}$, confirms that this phenotype is not caused by the inefficient or improper expression of the recombinant protein. In agreement with Merz et al. (1996), we did not observe significant traversal of T84 cells by piliated,
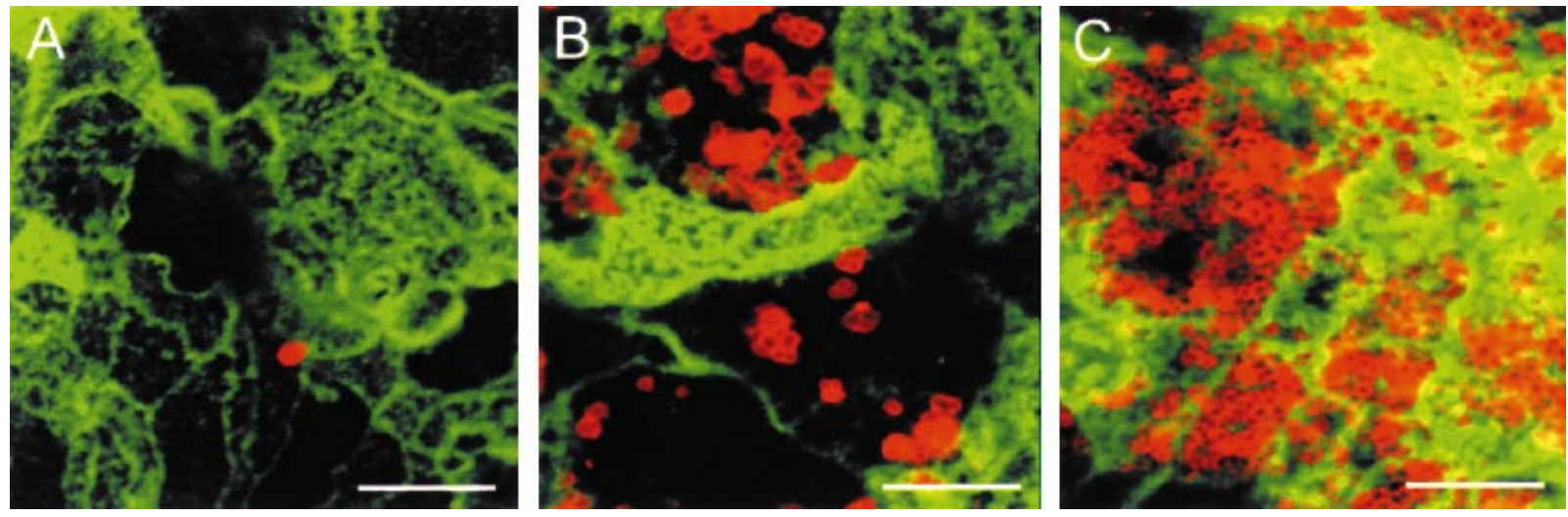

Fig. 1. Adherence of $N$. gonorrhoeae to the apical surface of polarized T84 monolayers. Polarized T84 monolayers cultured on Transwell polycarbonate filters were infected for $4 \mathrm{~h}$ with unpiliated $\left(\mathrm{P}^{-}\right)$gonococci expressing Opa 50 ( $\mathrm{A}$, strain N303) or Opa $52(\mathrm{~B}$, strain N309) and gonococci expressing pili but no Opa protein $\left(\mathrm{P}^{+} \mathrm{Opa}^{-} ; \mathrm{C}\right.$, strain N496). Filters were then fixed in formaldehyde and stained for immunofluorescence by double-labelling for bacteria (red) using rat-anti MS11 antiserum (AK231) and secondary Cy3-conjugated goat anti-rat antibodies, and for F-actin (green) by FITC-labelled phalloidin as outlined in Experimental procedures. Specimens were analysed by confocal laser scanning microscopy, and a representative $x-y$ plane taken from the apical surface of infected monolayers is presented. The scale bars represent $10 \mu \mathrm{m}$. 
non-opaque neisserial strains within $24 \mathrm{~h}$ of infection. In order to determine how the co-expression of these two adhesins affects transmigration, infection assays were also performed with piliated gonococcal strains that express the recombinant Opa proteins (Fig. 2B). Within the examined period of infection (up to $24 \mathrm{~h}$ ), the expression of pilus or Opa 50 , either separately or together, did not influence the levels of gonococci appearing in the basolateral chamber compared with that seen with the non-piliated, non-opaque strain. It is likely that background levels of transmigration may result from the phase-variable switching of Opa phenotypes during bacterial growth in the apical reservoir. However, the existence of 11 opa loci in the gonococcal genome precludes the generation of a genotypically opa ${ }^{-}$strain to test this assumption. Opa 52

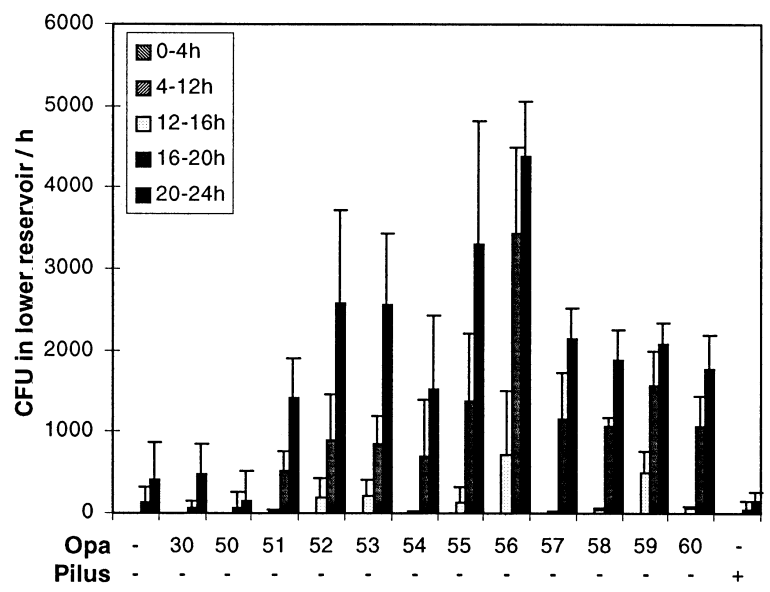

C

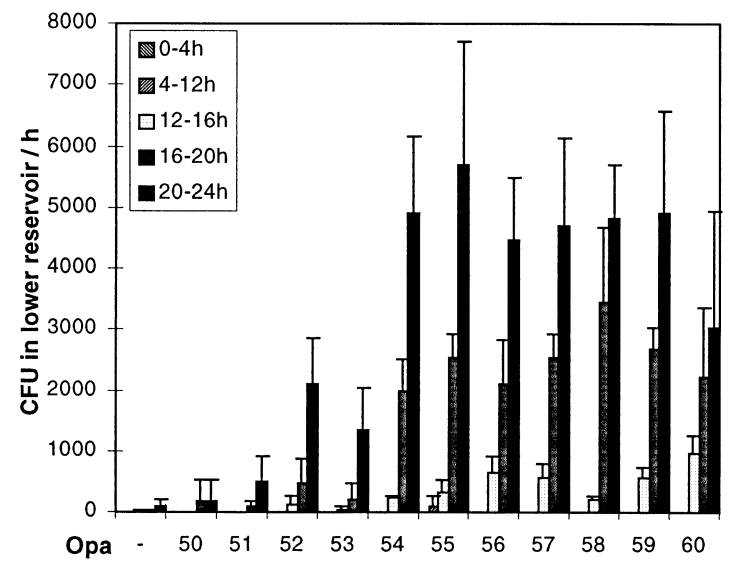

expression clearly resulted in an increased number of gonococci appearing in the basolateral chamber, and pilus expression did not significantly influence this. Interestingly, the level of transmigration mediated by $\mathrm{Opa}_{52}$ in the non-piliated strain N280 background (N547) was reduced compared with that seen in the $\mathrm{N} 279$ background (N309) when these two strains were used in parallel experiments (data not shown); however, the reason for this difference is uncertain.

Recombinant $E$. coli DH5 strains expressing each of the Opa proteins encoded by $N$. gonorrhoeae strain MS11 were tested for their ability to traverse the T84 monolayer system to determine whether Opa protein expression in a distant bacterial species was itself sufficient to allow transmigration. Consistent with results obtained using the
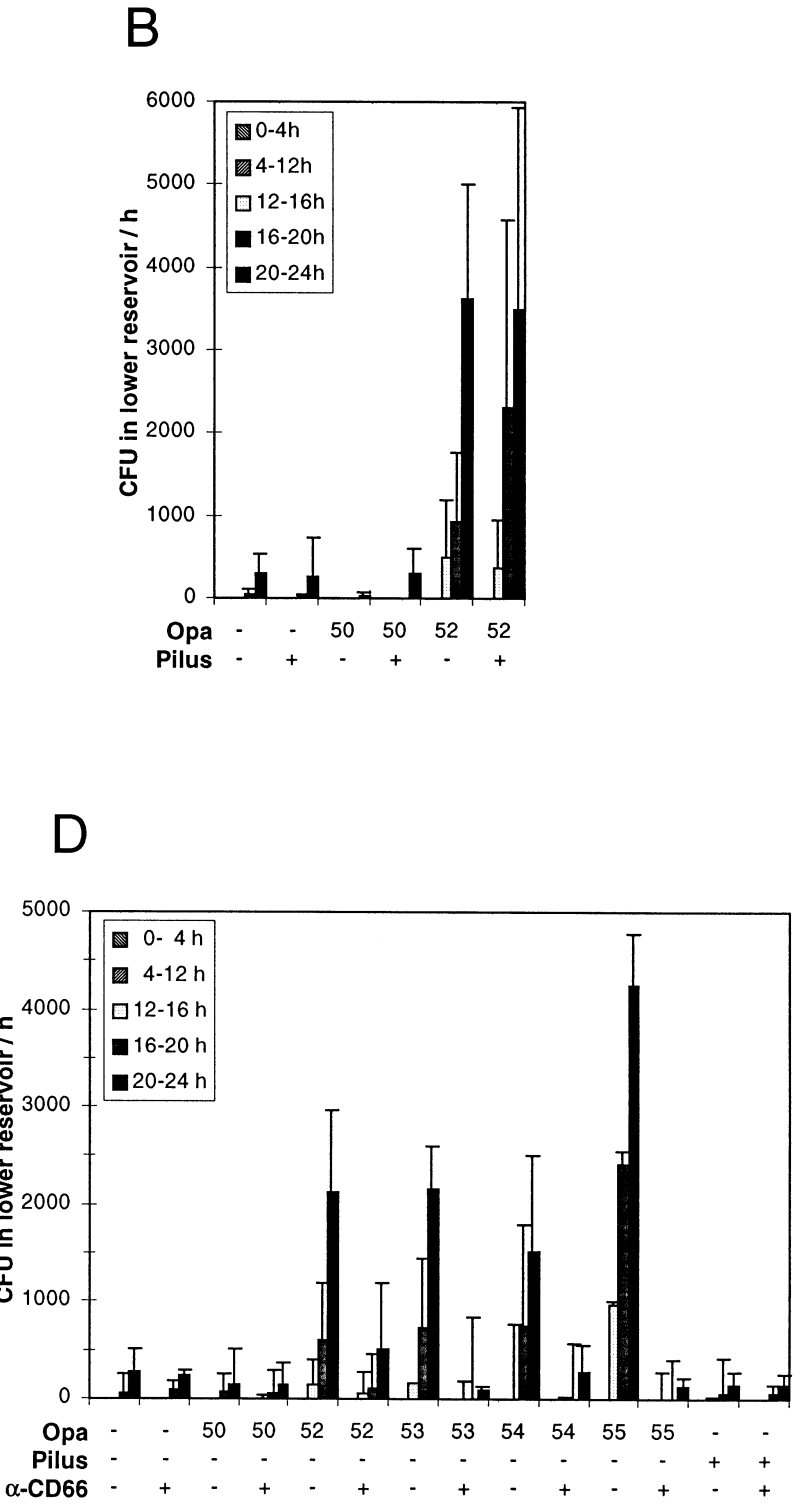

(C) 1998 Blackwell Science Ltd, Molecular Microbiology, 30, 657-671 
gonococcal-expressed Opa proteins, Opa proteins other than $\mathrm{Opa}_{50}$ mediated traversal of the epithelial barrier more than did the parental $E$. coli $\mathrm{DH} 5$ containing the Hermes-10 expression vector alone (Fig. 2C). Of these, the $E$. coli strain expressing $\mathrm{Opa}_{51}$ was least efficient in mediating bacterial traversal, although bacterial levels in the lower reservoir were at least fourfold higher than that of the Opa ${ }_{50}$-expressing strain.

\section{Expression of CD66 receptor proteins by polarized T84 monolayers}

The Opa proteins seen to mediate adherence to and traversal across T84 monolayers have been shown previously to recognize specifically up to four different members of the CD66 carcinoembryonic family of receptors that are differentially expressed on endothelia, epithelia and phagocytic cells (Chen and Gotschlich, 1996; Bos et al., 1997; Chen et al., 1997; Gray-Owen et al., 1997a,b). In order to determine the expression pattern of CD66 receptors on T84 cells, we performed an immunoblot analysis of total protein extracted from monolayers grown on filter supports and treated similar to those used in the infection assays. The CD66 cross-reactive monoclonal antibody D14HD11 recognized proteins of approximately $200 \mathrm{kDa}, 160 \mathrm{kDa}$ and $95 \mathrm{kDa}$ (Fig. 3A). As indicated by their electrophoretic mobility (Fig. 3A, lane 1) in comparison with CD66 members expressed by stably transfected HeLa cell lines, this generally corresponds with the sizes of CD66e (Fig. 3A, lane 3), CD66a (Fig. 3A, lane 4) and CD66c (Fig. 3A, lane 2) respectively. The $95 \mathrm{kDa}$ protein expressed by T84 cells has an apparent molecular weight slightly higher than that seen in the HeLa-NCA cell line (Fig. 3A, compare lanes 1 and 2). A replicate blot probed with the CD66cspecific monoclonal antibody 9A6 was therefore used to confirm that this protein is expressed (data not shown), as CD66b typically co-migrates with CD66c. The heterogeneous migration patterns seen in different cell types are a common feature of highly glycosylated proteins such as those of the CD66 family. Unfortunately, the lack of antibodies available that are capable of distinguishing between CD66a and CD66e prevents the conclusive identification of these proteins based on immunological characteristics alone. We therefore used a semi-quantitative reverse transcriptase (RT)-PCR approach employing oligonucleotide primers for the specific amplification of individual CD66 gene fragments (Table 1) in order to confirm the expression patterns indicated by immunoblot analysis. Glyceraldehyde-3-phosphate dehydrogenase (GAPDH), a constitutively expressed housekeeping gene (Wong et al., 1994), was used as an internal control in each amplification reaction. Stably transfected HeLa cell lines expressing individual CD66 receptors were used as positive controls for all primer sets. The respective RT-PCR products of uninfected T84 monolayers are shown in Fig. 3B. Using this approach, PCR products were obtained that are consistent with the expression of CD66a, CD66c and CD66e by T84 monolayers. Although the size of the CD66a RT-PCR product from T84 cells was lower than that obtained from the CD66a-expressing HeLa cell line (Fig. $3 \mathrm{~B}$, compare lanes 5 and 6 ), a repetition of this experiment with another CD66a-specific primer set confirmed the presence of CD66a mRNA expression by T84 cells (data not shown). Interestingly, the migration of CD66a RT-PCR products obtained using RNA isolated from infected T84 monolayers existed as a doublet corresponding to the

Fig. 2. Time course and CD66 dependency of the traversal of T84 monolayers by Opa-expressing N. gonorrhoeae and E. coli. The apical pole of polarized T84 monolayers cultured on Transwell polycarbonate filters was infected for $24 \mathrm{~h}$ with gonococcal (A, B and D) or E. coli (C) strains expressing defined recombinant Opa proteins and/or pili in the absence (A-C) or presence (D) of anti-CD66 antibodies as indicated. Colony-forming units (cfus) of bacteria passing into the basolateral reservoir during the indicated time intervals were determined by plating bacteria from the culture medium of the lower reservoir onto GC agar at $4 \mathrm{~h}, 12 \mathrm{~h}, 16 \mathrm{~h}, 20 \mathrm{~h}$ and $24 \mathrm{~h}$ after infection. At each of these time points, Transwell inserts with the infected monolayer were transferred to a new well containing fresh medium in the lower reservoir. Assays were performed in at least three independent experiments with two to eight filters per strain per assay. Data illustrated represent the means and standard deviations of a representative experiment performed, except in (B) where means + standard deviations were calculated instead using the three median values from two independent experiments performed in duplicate. All data were normalized by calculating cfu appearing in the lower reservoir per hour in order to simplify comparison of transmigration rates throughout the infection period. A. Opa-dependent transcytosis of T84 monolayers. The gonococcal strains used were non-piliated $\left(\mathrm{P}^{-}\right)$and expressing no Opa protein $\left(O p a^{-}\right.$, strain N302), chromosomally encoded $\mathrm{Opa}_{30}$ (strain N483) or recombinant Opa 50 (strain N303), Opa ${ }_{51}$ (strain N305), Opa 52 (strain N309), $\mathrm{Opa}_{53}$ (strain N304), Opa 54 (strain N311), Opa 55 (strain N307), Opa 56 (strain N308), Opa 57 (strain N313), Opa 58 (strain N312), Opa 59 (strain $\mathrm{N} 306$ ) or $\mathrm{Opa}_{60}$ (strain $\mathrm{N} 310$ ) or piliated $\left(\mathrm{P}^{+}\right)$and non-opaque $\left(\mathrm{Opa}^{-}\right.$; strain N496).

B. Influence of pilus expression on Opa-dependent transcytosis. The gonococcal strains used were non-piliated $\left(\mathrm{P}^{-}\right)$expressing either no Opa protein $\left(\mathrm{Opa}^{-}\right.$, strain N302) or recombinant Opa 50 (strain N303) or Opa 52 (strain N547, phenotypically selected $\mathrm{P}^{-}$variant) or piliated $\left(\mathrm{P}^{+}\right.$) variants expressing either no Opa protein (Opa- ${ }^{-}$, strain N280) or recombinant Opa 50 (strain N541) or Opa 52 (strain N547).

C. Transcytosis of Opa-expressing E. coli. The DH5 strains used carry the IPTG-inducible expression vector Hermes-10 as a control (Opa ${ }^{-}$, strain $\mathrm{H} 1887)$ or derivatives directing the expression of recombinant Opa proteins $\left(\mathrm{Opa}_{50}\right.$, strain $\mathrm{H} 1888$; Opa $\mathrm{O}_{51}$, strain $\mathrm{H}_{1903 ;} \mathrm{Opa}_{52}$, strain H1907; Opa ${ }_{53}$, strain H1902; Opa 54 , strain H1909; Opa 55 , strain H1905; Opa ${ }_{56}$, strain H1906; Opa 57 , strain H1911; Opa 58 , strain H1910; $\mathrm{Opa}_{59}$, strain $\mathrm{H} 1904$ and $\mathrm{Opa}_{60}$, strain $\mathrm{H} 1908$ ).

D. Effect of antibody blockage of CD66 on Opa-dependent transcytosis. The gonococcal strains used were non-piliated $\left(\mathrm{P}^{-}\right)$expressing either no Opa protein $\left(\mathrm{Opa}^{-}\right.$, strain N302) or recombinant Opa 52 (strain N309), Opa 53 (strain N304), Opa 54 (strain N311) or Opa 55 (strain N307) or were piliated $\left(\mathrm{P}^{+}\right)$expressing no Opa protein $\left(\mathrm{Opa}^{-}\right.$, strain $\left.\mathrm{N496}\right)$. Infection was performed for $24 \mathrm{~h}$ in the presence or absence of polyclonal anti-CD66 antibodies cross-reacting with all CD66 receptors co-expressed on T84 cells. 

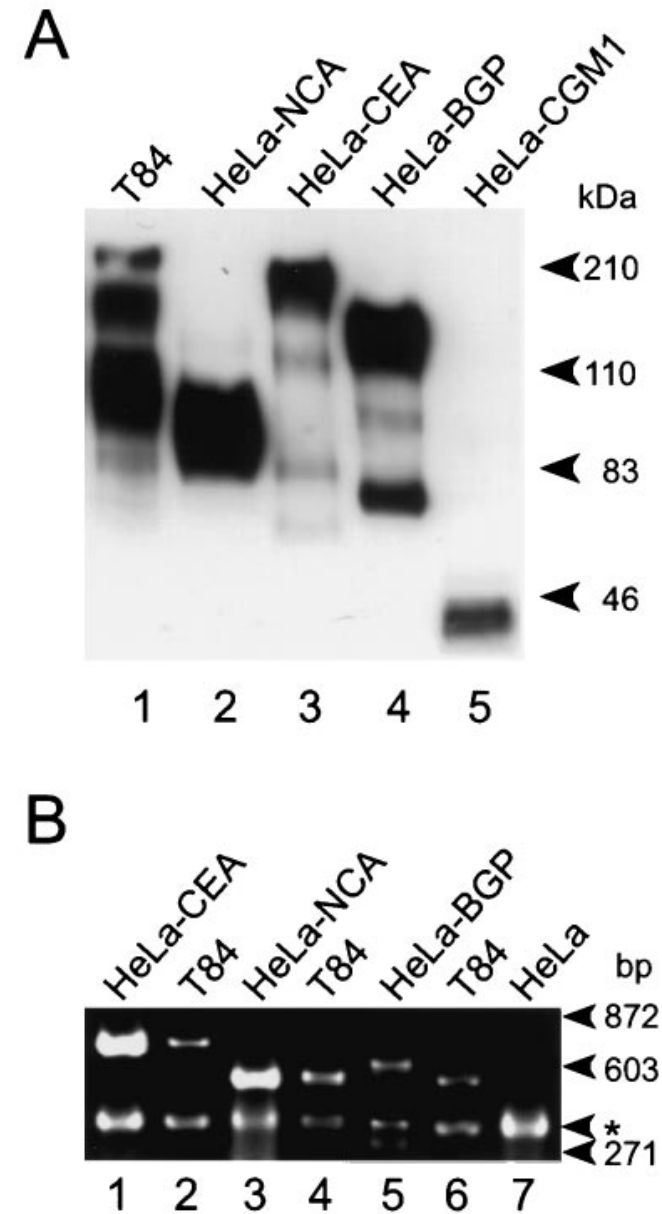

Fig. 3. Analysis of CD66 expression in polarized T84 monolayers. Polarized T84 monolayers grown on Transwell polycarbonate filters similar to those used for transepithelial traversal experiments or stably transfected HeLa cell lines expressing CD66a (HeLa-BGPa), CD66c (HeLa-NCA), CD66d (HeLa-CGM1a) or CD66e (HeLa-CEA) grown on plastic tissue culture dishes were extracted by TRIzol reagent, and the expression of CD66 family members was analysed by immunoblotting of total protein $(A)$ or semi-quantitative RT-PCR using isolated total RNA (B).

A. Total protein prepared from TRIzol extracts was separated on $10 \%$ gels by SDS-PAGE, transferred to PVDF membranes and probed with monoclonal mouse anti-CD66 antibody (clone D14HD11) followed by horseradish peroxidase-conjugated goat anti-mouse antibodies. Immunoblots were developed by enhanced chemiluminescence (ECL). The electrophoretic mobility of molecular weight markers is indicated.

B. Total RNA prepared from TRlzol extracts was subjected to semi-quantitative duplex RT-PCR using primer pairs specific for BGPa (CD66a), NCA (CD66c) or CEA (CD66e). GAPDH-specific primers that generate a $306 \mathrm{bp}$ fragment from cDNA served as an internal control (amplified GADPH fragment indicated by a star).

individual bands obtained from uninfected HeLa-CD66a and T84 cells respectively (data not shown). The reason for these differences are not clear at this time. However, the potential induction of differential splice variants (Barnett et al., 1993; Thompson et al., 1991) by neisserial infection is currently being explored.
Traversal of T84 monolayer requires Opa-mediated binding to CD66 receptors

Immunofluorescence staining and confocal laser scanning microscopic analysis of infected T84 monolayers was performed in order to compare gonococcal binding with the expression pattern of CD66 receptors. Co-localization of CD66 receptors with adherent $\mathrm{Opa}_{52}$-expressing gonococci clearly indicates the efficient recruitment of receptor by this Opa (Fig. 4A-D), while no similar accumulation of CD66 antigens occurred in association with bound $\mathrm{Opa}_{50^{-}}$ expressing bacteria (data not shown). Receptor association patterns seen when using gonococci expressing either $\mathrm{CD66a}$ or CD66e-specific Opa proteins $\left(\mathrm{Opa}_{53}\right.$ and $\mathrm{Opa}_{55}$ respectively) were indistinguishable from those seen for $\mathrm{Opa}_{52}$-expressing bacteria (data not shown), indicating that either of these receptors could also mediate bacterial binding to T84 cells. Confocal laser scanning microscopy in an $x-z$ plane illustrated that $C D 66$ receptor expression is polarized, occurring at the apical surface of monolayers (compare Fig. 4F and G). Occasionally, intracellular bacteria were seen to be associated with CD66 proteins, suggesting a continued association between Opa and CD66 during transmigration. In the majority of cases, however, intracellular bacteria did not associate with CD66 labelling (arrow in Fig. 4F-H, arrows point to the position of a traversing bacterium).

In order to correlate bacterial binding to CD66 receptors on the apical surface directly with their ability to traverse the monolayer, infection experiments were repeated in the presence and in the absence of polyclonal anti-CD66 antibodies that cross-react with all three $\mathrm{CD} 66$ receptors expressed on T84 cells. Non-piliated $\left(\mathrm{P}^{-}\right)$gonococcal strains that express Opa proteins representative of the four CD66 binding specificities were used: $\mathrm{Opa}_{52}$ (binds CD66a, CD66c, CD66d and CD66e); Opa 53 (CD66a specific); $\mathrm{Opa}_{55}$ (CD66e specific); and $\mathrm{Opa}_{54}$ (binds CD66a and $\mathrm{CD66e})$. Non-piliated $\left(\mathrm{P}^{-}\right)$gonococcal strains expressing $\mathrm{Opa}_{50}$ or no Opa $\left(\mathrm{Opa}^{-}\right)$and a piliated, but nonopaque $\left(\mathrm{P}^{+} \mathrm{Opa}^{-}\right)$strain were also used as non-CD66 binding controls. Confocal laser scanning microscopy of the infected samples confirmed that the antibodies competitively inhibited binding of CD66-specific, Opa-expressing strains to the T84 monolayer (compare Fig. $4 \mathrm{I}$ and J), but did not affect interactions seen with either $\mathrm{Opa}_{50^{-}}$or pilusexpressing strains (data not shown). Importantly, no crossreactive binding of the CD66-specific antiserum was seen with isolated gonococci by direct immunofluorescence staining, supporting the premise that its inhibitory effects are caused by antibody binding of CD66 receptors directly (data not shown). A clear inhibition of transmigration was also seen for all strains expressing CD66-specific Opa proteins, while no obvious effect of antibody on transmigration by the other strains was seen (Fig. 2D). Consistent results

(C) 1998 Blackwell Science Ltd, Molecular Microbiology, 30, 657-671 
Table 1. Primer sets for specific amplification of CD66 family and control transcripts by RT-PCR.

\begin{tabular}{|c|c|c|c|c|c|}
\hline Transcript & Primer & Sequence & $\begin{array}{l}\mathrm{T}_{\text {annealing }} \\
\left({ }^{\circ} \mathrm{C}\right)\end{array}$ & $\begin{array}{l}\text { Fragment } \\
\text { length }\end{array}$ & Reference \\
\hline CEA (CD66e) & $\begin{array}{l}\text { CEA-5' } \\
\text { CEA-3' }\end{array}$ & $\begin{array}{l}\text { 5'-CCATGGAGTCTCCCTCG-3' } \\
\text { 5'-GTAGCTTGCTGTGTCATTTC-3' }\end{array}$ & 56 & $641 \mathrm{bp}$ & Thompson et al. (1993) \\
\hline NCA (CD66c) & $\begin{array}{l}\text { NCA-5' } \\
\text { NCA-3' }\end{array}$ & $\begin{array}{l}\text { 5'-TTCTTCTACTCGCCCACAAC-3' } \\
\text { 5'-GTTCCTTTTGACGCTGAGTA-3' }\end{array}$ & 58 & $474 \mathrm{bp}$ & Thompson et al. (1993) \\
\hline BGP (CD66a) & $\begin{array}{l}\text { BGP2-5' } \\
\text { BGP2-3' }\end{array}$ & $\begin{array}{l}\text { 5'-ACAGTCAAGACGATCATAGT-3' } \\
\text { 5'-ATCTTGTTAGGTGGGTCATT-3' }\end{array}$ & 56 & $530 \mathrm{bp}$ & $\begin{array}{l}\text { R. Kammerer and S. Hahn, } \\
\text { personal communication }\end{array}$ \\
\hline GAPDH & $\begin{array}{l}\text { GADPH-5' } \\
\text { GADPH-3' }\end{array}$ & $\begin{array}{l}\text { 5'-CGGAGTCAACGGATTTGGTCGTAT-3' } \\
\text { 5'-AGCCTTCTCCATGGTGGTGAAGAC-3' }\end{array}$ & $56-58^{a}$ & $306 \mathrm{bp}$ & Wong et al. (1994) \\
\hline
\end{tabular}

a. GAPDH primers were used in duplex RT-PCR with annealing temperatures being determined by the co-amplifying of a CD66-specific primer pair.

were obtained by a similar analysis of the effect of polyclonal anti-CD66 antibodies on transmigration by the recombinant Opa-expressing E. coli strains (data not shown). As there is no known Opa protein that binds only CD66c, a monolayer infected with the $\mathrm{Opa}_{52}$-expressing gonococcal strain was stained with the CD66c-specific monoclonal antibody 9A6 and analysed by confocal laser scanning microscopy. Similar to that shown previously when using the stably transfected HeLa cell line expressing CD66c alone (HeLa-NCA; Gray-Owen et al., 1997a), an obvious recruitment of CD66c to the site of bacterial binding was observed (data not shown).

Time course of T84 cell entry and traversal by Opa expressing $\mathrm{N}$. gonorrhoeae

The kinetics of gonococcal uptake into T84 cells was measured by the addition of gentamicin to apical and basolateral reservoirs after various time points and then recovering viable intracellular bacteria by saponin lysis of the T84 cell membranes. As shown in Fig. 5A, intracellular gonococci expressing $\mathrm{Opa}_{52}$ could already be recovered after $3 \mathrm{~h}$ infection, with the number of intracellular bacteria increasing with the infection time before gentamicin treatment. The time required by traversing bacteria to be internalized into the monolayer initially was determined instead by adding gentamicin only to the apical reservoir and then allowing the infection to continue (Fig. 5B). When gentamicin was added $3 \mathrm{~h}$ after infection, very few bacteria were seen in the lower reservoir even after $28 \mathrm{~h}$. Consistent with the fact that apical uptake of bacteria is an ongoing process (Fig. 5A), postponing the gentamicin treatment until $6 \mathrm{~h}$ allowed low levels $(20-30 \%$ of control) of transmigration to occur, and longer intervals allowed consistently more bacteria to be recovered ( $30-50 \%$ of control). Gentamicin treatment at later time points did not obviously reduce the level of bacteria recovered, suggesting that bacteria recovered by $24 \mathrm{~h}$ after infection had all penetrated the apical membrane by this time.

In order to determine whether a similar period was necessary for transepithelial traversal mediated by Opa proteins with different $\mathrm{CD} 66$ binding patterns, representative CD66-specific, Opa-expressing strains were used in a similar gentamicin assay in parallel to non-opaque, $\mathrm{Opa}_{50^{-}}$ expressing and a non-opaque, pilus-expressing (Opa ${ }^{-}$ $\mathrm{P}^{+}$) strain. In all cases, about $10 \%$ of control levels of bacteria were recovered by gentamicin treatment after $6 \mathrm{~h}$ (data not shown). As $\mathrm{Opa}_{53}$ and $\mathrm{Opa}_{55}$ are specific for CD66a and CD66e, respectively, these results indicate that the specific recruitment of two different receptors results in a similar kinetics of bacterial uptake at the apical surface.

The transepithelial traversal of $\mathrm{N}$. gonorrhoeae and E. coli does not disrupt the barrier function of T84 monolayers

Scanning electron microscopic (SEM) analysis of infected monolayers displayed very few $\mathrm{Opa}_{50}$-expressing (Fig. 6A) or transparent $\left(\mathrm{Opa}^{-}\right.$; data not shown) gonococci on the surface of infected cells. These bacteria typically appeared as small, loosely associated clusters without any obvious specific interaction with the apical surface, and no microvilli reorganization or internalization of bacteria was evident even after $24 \mathrm{~h}$ of infection. In strong contrast to this, infection by the $\mathrm{Opa}_{52}$-expressing strain resulted in large numbers of individually associated bacteria initially showing a tight binding and bending of microvilli (Fig. 6B). Later, bacteria at various stages of interaction were evident (e.g. Fig 6C, the plasma membrane fusing above an internalized bacterium is indicated by an arrow). The general disruption of normal microvilli distribution within the area of $\mathrm{Opa}_{52}$-mediated binding is suggestive of major rearrangements in the underlying cytoskeletal architecture.

Transmission electron microscopic (TEM) analysis indicated that primary $\mathrm{Opa}_{52}$-mediated interactions involve adherence to the tip of cellular microvilli (Fig. 6D), while subsequent engulfment seemed to involve the restructuring of microvilli structures leading ultimately to an intimate contact between bacterial and cellular membranes (Fig. $6 \mathrm{E})$. The quantity of engulfed and intracellular gonococci increased with time throughout the period of infection, 

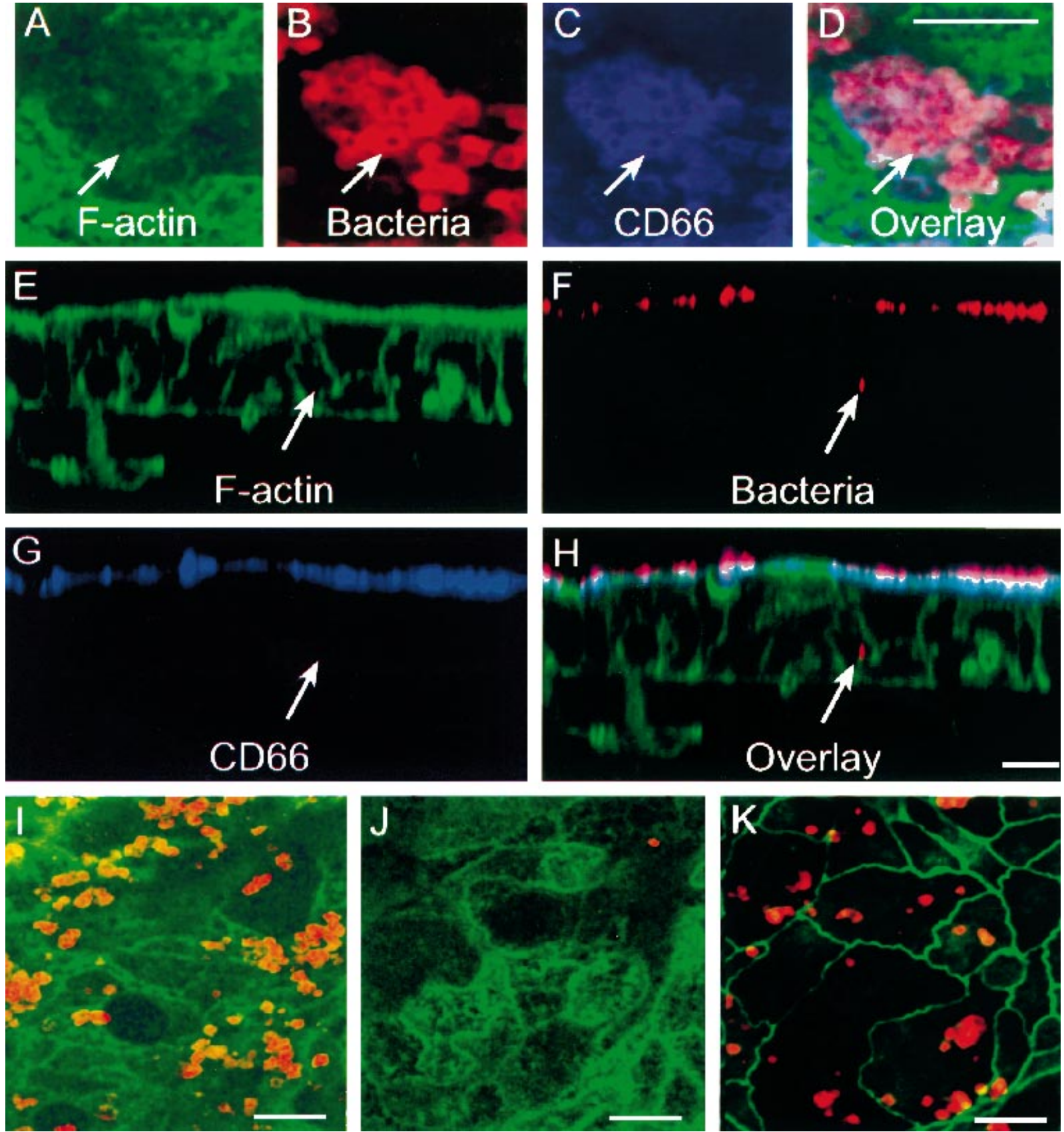

Fig. 4. Confocal microscopic analysis of T84 monolayer traversal by Opa-expressing $N$. gonorrhoeae. The apical pole of polarized T84

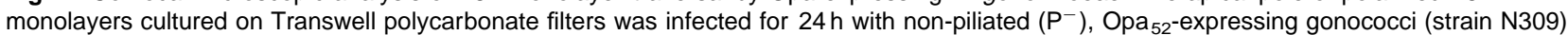
in the absence $(A-I$ and $K$ ) or presence $(J)$ of polyclonal anti-CD66 antibodies. Filters were then fixed in formaldehyde and stained for immunofluorescence.

A-H. Specimens were triple stained for F-actin using FITC-phalloidin (green in A, D, E and H), bacteria using rat anti-MS11 antiserum (AK231) and secondary Cy5-conjugated goat anti-rat antibodies (red in B, D, F and H) and CD66 using monoclonal antibody clone D14HD11 and secondary lissamine rhodamine (LRSC)-conjugated goat anti-mouse antibodies (blue in C, D, G and H).

$\mathrm{I}$ and J. Monolayers were double stained for bacteria (red) and F-actin (green) as described in the legend to Fig. 1.

$\mathrm{K}$. The monolayer was double stained for ZO-1 (green) using rabbit anti-ZO-1 antibodies and secondary Cy5-conjugated goat anti-rabbit antibodies, and for bacteria (red) using rat anti-MS11 antiserum (AK231) and secondary Cy3-conjugated goat anti-rat antibodies.

Representative confocal $x-y$ planes taken from the apical surface (A-D and I-K) or a representative $x-z$ cross-section through an infected monolayer $(E-H)$ are presented. The arrows in $(A-D)$ point to one representative bacterium co-localizing with increased CD66 staining. The arrows in $(\mathrm{E}-\mathrm{H})$ point to the position of a bacterium traversing the monolayer. The scale bars represent $10 \mu \mathrm{m}$. 
and all stages of internalization were apparent at later time points (data not shown). Transparent and Opa ${ }_{50}$-expressing gonococci were found to be neither associated nor intracellular in the T84 monolayer, even after $24 \mathrm{~h}$ of infection (data not shown). Intracellular Opa ${ }_{52}$-expressing bacteria appeared to move along a transcellular pathway (Fig. $6 \mathrm{~F}$, arrow pointing to an intracellular bacterium and an increased magnification of this shown in Fig. 6G). Bacteria seen were typically single or diplococci and continued to be enclosed by a tightly associated phagosomal membrane throughout traversal (arrow in Fig. 6G). No obvious disruption of the cellular architecture correlated with either intracellular gonococci or with the Opa-mediated transepithelial traversal seen in Fig. 2, and tight junctions were visible at the apical border of adjacent cells infected with Opa ${ }_{52}$-expressing gonococci at all time points investigated (arrows in Fig. 6D and H). Confocal microscopic analysis of samples stained using the ZO-1 specific antibody also illustrates that a uniform staining of apical borders was maintained even after $24 \mathrm{~h}$ of infection with Opa $_{52}$-expressing gonococci (Fig. 4K). Consistent with this assertion, the transepithelial electrical resistance (TEER) of T84 cell

A

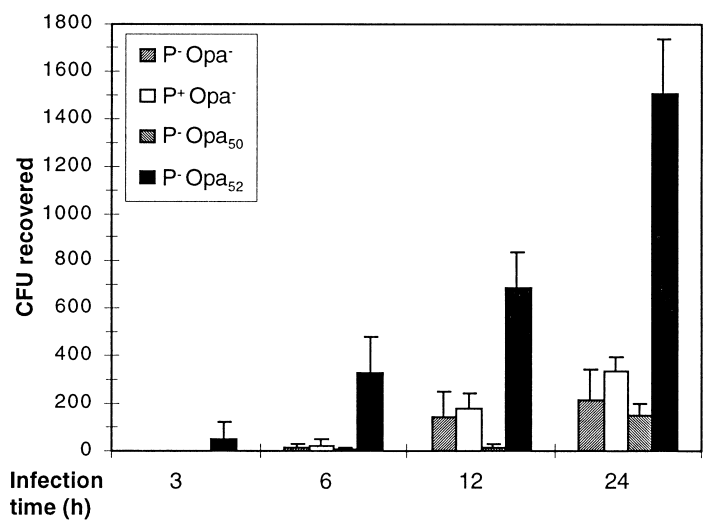

B

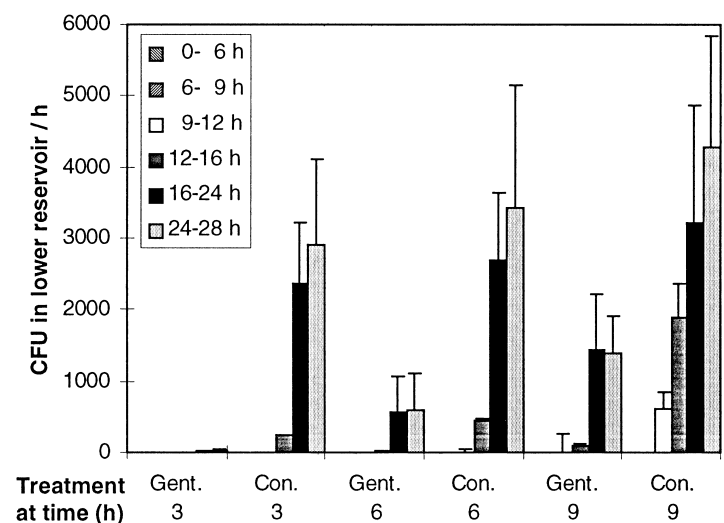

monolayers typically remained above $700 \Omega \mathrm{cm}^{-2}$ during the infection by both recombinant gonococci and $E$. coli strains (data not shown), thus confirming the maintenance of barrier function throughout these assays.

\section{Discussion}

Previous studies have used various cellular and tissue models to yield a morphological description of the early stages of neisserial infection, and there is considerable evidence that the pathogenic Neisseriae can enter epithelial cells (Silverstein et al., 1977; McGee et al., 1983; Shaw and Falkow, 1988; Chen et al., 1991). For example, infection of organ cultures derived from fallopian tubes (FTOCs) or the nasopharynx (NPOCs) has demonstrated neisserial entry into epithelial cells at the apical surface, traversal into the basal region and movement into the stromal matrix (McGee et al., 1981; 1983; Stephens et al., 1983; Stephens and Farley, 1991). Clinical isolates of $N$. meningitidis have also been shown to transmigrate across polarized T84 monolayers within 12-24h of infection (Pujol et al., 1997), while piliated gonococci appeared in the basolateral chamber only after 36-48 h (Merz et al., 1996). Non-piliated isogenic strains transmigrated at levels much below that of

Fig. 5. Time requirement for Opa-dependent traversal of T84 monolayers by $N$. gonorrhoeae.

A. Time requirement and Opa dependency of the apical invasion of the T84 monolayer. The apical pole of polarized T84 monolayers cultured on Transwell polycarbonate filters was infected with gonococcal strains that were non-piliated expressing either no Opa protein $\left(\mathrm{P}^{-} \mathrm{Opa}^{-}\right.$, strain $\left.\mathrm{N} 302\right)$ or recombinant Opa $\mathrm{O}_{50}\left(\mathrm{P}^{-} \mathrm{Opa}_{50}\right.$, strain N303) or $\mathrm{Opa}_{52}\left(\mathrm{P}^{-} \mathrm{Opa}_{52}\right.$, strain N309) or piliated and non-opaque $\left(\mathrm{P}^{+} \mathrm{Opa}^{-}\right.$, strain N280). After the time period indicated $(3 \mathrm{~h}, 6 \mathrm{~h}, 12 \mathrm{~h}$ and $24 \mathrm{~h})$, gentamicin $\left(100 \mu \mathrm{g} \mathrm{ml}^{-1}\right)$ was added to both reservoirs for $2 \mathrm{~h}$ in order to kill extracellular bacteria. Colony-forming units (cfus) of intracellular bacteria surviving gentamicin treatment were determined by saponin lysis of the monolayer and plating bacteria onto GC agar.

B. The apical pole of polarized T84 monolayers cultured on Transwell polycarbonate filters was infected with a non-piliated $\left(\mathrm{P}^{-}\right)$ gonococcal strain expressing recombinant $\mathrm{Opa}_{52}$ (N309) for $28 \mathrm{~h}$. After the time period indicated $(3 \mathrm{~h}, 6 \mathrm{~h}$ or $9 \mathrm{~h})$, gentamicin $\left(100 \mu \mathrm{g} \mathrm{ml}^{-1}\right.$, indicated as Gent) was added to the upper reservoir for $2 \mathrm{~h}$ in order to kill all extracellular bacteria that had not yet entered the monolayer. After this time, a lower concentration of gentamicin $\left(20 \mu \mathrm{g} \mathrm{ml}^{-1}\right)$ was kept in the upper reservoir until the end of the experiment. The addition of gentamicin was omitted in otherwise identically treated filters that served as controls (indicated as Con). Colony-forming units (cfus) of bacteria traversed in the time intervals indicated $(0-6 \mathrm{~h}, 6-9 \mathrm{~h}, 9-12 \mathrm{~h}$, $12-16 \mathrm{~h}, 16-24 \mathrm{~h}$ and $24-28 \mathrm{~h}$ ) were determined by plating bacteria from the culture medium in the lower reservoir onto GC agar at $6 \mathrm{~h}$, $9 \mathrm{~h}, 12 \mathrm{~h}, 16 \mathrm{~h}, 24 \mathrm{~h}$ and $28 \mathrm{~h}$ after infection. At each of these time points, Transwell inserts with the infected monolayer were transferred to a new well with fresh medium in the lower reservoir. Assays were performed in at least three independent experiments with two to eight filters per strain and assay. Data illustrated represent the mean and standard deviations of a representative experiment and were normalized by calculating cfus appearing in the lower reservoir per hour in order to simplify comparison of transcytosis rates throughout the infection period. 

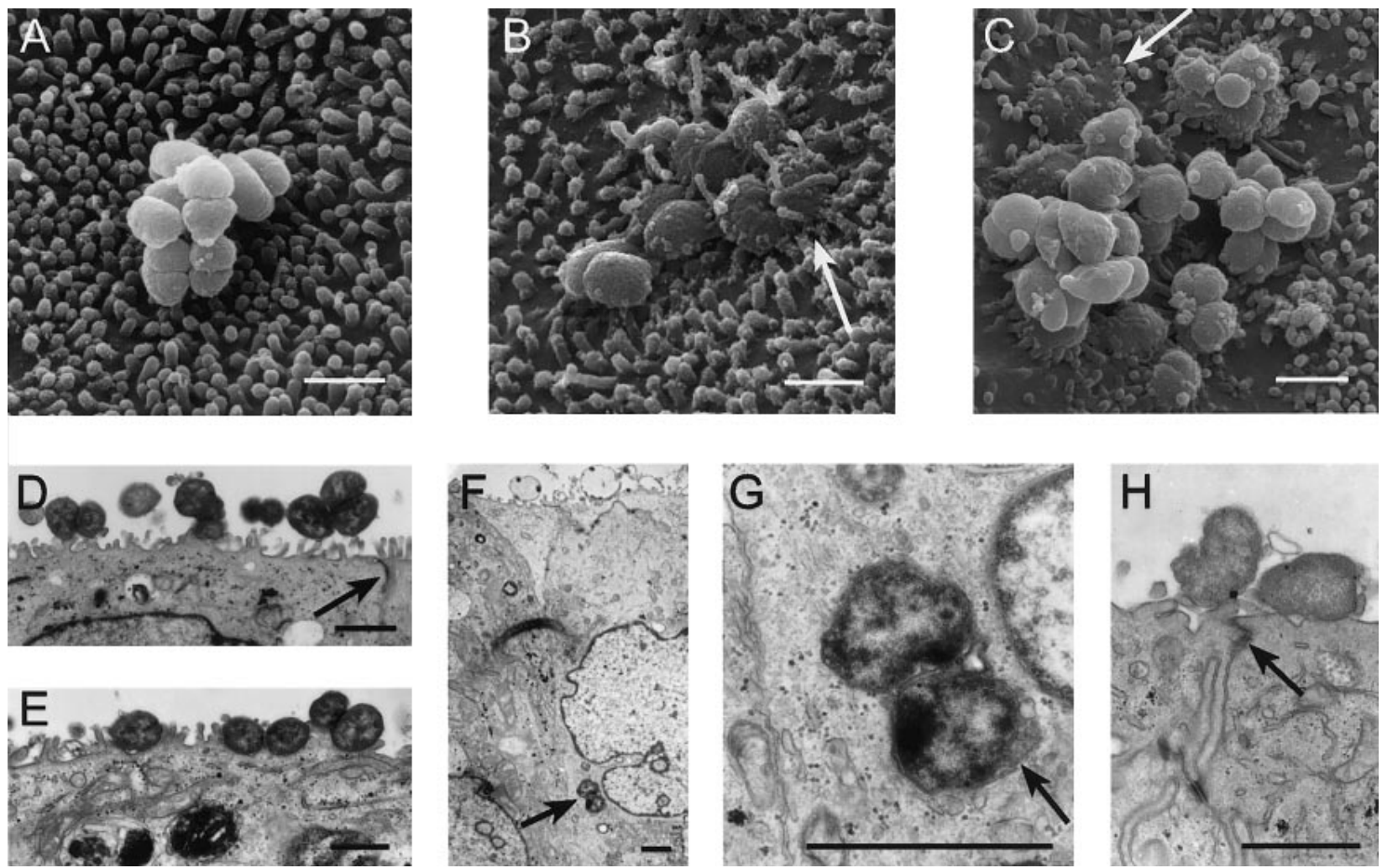

Fig. 6. Ultrastructural characterization of the Opa-dependent traversal of polarized T84 monolayers by $N$. gonorrhoeae. The apical pole of polarized T84 monolayers cultured on Transwell polycarbonate filters was infected with non-piliated gonococci expressing Opa 50 (A) or Opa 52 $(B-H)$ for $4 \mathrm{~h}(\mathrm{D}$ and $\mathrm{E})$ or $24 \mathrm{~h}(\mathrm{~A}-\mathrm{C}$ and $\mathrm{F}-\mathrm{H})$. Cells were then fixed, processed and analysed by scanning electron microscopy (SEM, A-C) or transmission electron microscopy (TEM, D-H) as outlined in Experimental procedures. Arrows indicate bent microvilli in close association with adherent $\mathrm{Opa}_{52}$-expressing bacteria $(B)$, the membrane protrusions fused on top of internalized bacteria $(C)$, tight junctions (D and $\left.H\right)$, intracellular bacteria traversing the monolayer $(F)$ or their close-fitting phagosomal membrane $(G)$. The scale bars represent $2 \mu \mathrm{m}$. For further details, see Results.

the piliated variants (Merz et al., 1996; Pujol et al., 1997), and pilus-mediated binding facilitates an intimate association between the bacterial and apical membranes (Pujol et al., 1997). This situation does, however, correlate with a reduced piliation of adherent bacteria, leading the authors to speculate that the tight adherence is mediated by some other adhesin. As the piliated bacteria used in these previous studies were $\mathrm{Opa}^{-}$(Merz et al., 1996; Pujol et al., 1997), the contribution of Opa proteins to neisserial interactions with T84 monolayers has not been explored previously. In the present study, we have demonstrated clearly that an effective traversal of polarized T84 monolayers by $N$. gonorrhoeae is mediated by distinct Opa protein variants that have previously been shown specifically to bind defined members of the CD66 epitope-containing carcinoembryonic antigen family $\left(\mathrm{Opa}_{51}-\mathrm{Opa}_{60}\right.$; Bos et al., 1997; Chen et al., 1997; Gray-Owen et al., 1997b). The efficiency of this process is evident from the fact that viable Opa-expressing N. gonorrhoeae and $E$. coli begin to pass into the lower reservoir as early as $12 \mathrm{~h}$ after infection (Fig. 2). Consistent with this, the CD66a, CD66c and
CD66e receptors were seen to be expressed by a combination of immunoblot and RT-PCR analysis (Fig. 3). A high density of CD66 proteins was also seen to co-localize with $\mathrm{Opa}_{52}$-expressing bacteria adherent at the apical surface of T84 cells (Fig. 4A-D), indicating the efficient recruitment of these receptors. Ultrastructural analysis reveals that a primary interaction with the tips of uniformly arranged microvilli subsequently leads to an intimate association between bacterial and cellular membranes (Fig. 6D and E). This process appears to involve a significant reorganization of the underlying cytoskeletal framework, as microvilli adjacent to tightly adherent bacteria typically retract (compare Fig. 6A, B and C). Once engulfed, intracellular gonococci exist as single bacteria or diplococci and apparently remain surrounded by a tightly associated phagosomal membrane (Fig. 6F and G), which is occasionally seen to contain CD66 receptors. The absence of CD66 antigens in association with most intracellular bacteria may indicate that the receptor is cycled away from the phagosome after bacterial internalization. Alternatively, this observation may result from a masking of the epitope recognized by

(C) 1998 Blackwell Science Ltd, Molecular Microbiology, 30, 657-671 
CD66-specific antibodies used in the immunocytochemical staining of samples, either by bacterial Opa-mediated association with the receptors or as a result of the presence of high levels of proteins, which become associated with the phagolysosomal vesicle (e.g. h-lamp). Previous studies have shown that gonococci can exist as large clusters of bacteria within a single vacuole (Apicella et al., 1996; Mosleh et al., 1997). However, urethral exudates from patients with gonococcal urethritis show that bacteria are engulfed as single organisms (Apicella et al., 1996). Whether the subsequent appearance of phagosomes containing multiple bacteria arise from the intracellular fusion of phagosomes or via bacteria replication is not yet certain. Pujol et al. (1997) displayed piliated meningococci occurring within a more spacious phagosome, suggesting that the phagocytic events that follow pilus vs. Opamediated uptake may be distinct.

The tight junction, or zonula occludens (ZO), is a narrow belt-like structure on the plasma membrane of transporting epithelial cells that wraps each cell circumferentially and adjoins it to its neighbours. This organization provides an efficient barrier restricting flow through the paracellular pathway (Madara, 1988). Ultrastructural analyses using confocal laser scanning microscopy, SEM and TEM indicate that the transmigration of gonococci that express CD66-specific Opa proteins occurs via a transcellular rather than a paracellular route (Figs $4 \mathrm{E}-\mathrm{H}$ and $6 \mathrm{~F}$ and $\mathrm{G})$. This is consistent with the fact that the monolayer's barrier function remains intact, as seen by both the continued presence of tight junctions (Figs $4 \mathrm{~K}$ and $6 \mathrm{D}$ and $\mathrm{H})$ and the maintenance of transepithelial electrical resistance (TEER) throughout infection experiments. This is clearly different from Salmonella typhimurium and the enteropathogenic E. coli (EPEC), which can disrupt the organization of tight junctions and barrier function of epithelial tissues to allow paracellular migration to occur (Wallis et al., 1986; Canil et al., 1993; Jepson et al., 1995; Philpott et al., 1996). Binding to the apical surface of epithelia is not strictly correlated with transmigration, however, as $\mathrm{H}$. pylori has been shown to adhere tightly to polarized T84 monolayers in a manner that resembles the gonococcal binding seen here, but does not enter these cells (Corthesy-Theulaz et al., 1996).

The indistinguishable characteristics of binding, engulfment and transmigration by recombinant gonococcal and E. coli strains expressing Opa proteins with different CD66 specificity patterns, as exemplified by $\mathrm{Opa}_{52}$ (binds CD66a, CD66c, CD66d and CD66e), Opa 53 (specific for CD66a) and $\mathrm{Opa}_{55}$ (specific for CD66e), suggests that either CD66a or CD66e can mediate the process of transepithelial traversal (Fig. 2). No CD66c-specific Opa protein has been identified, and so the specific contribution of this receptor in bacterial binding and engulfment cannot be discerned. Immunocytochemical analysis of samples stained with the
CD66c-specific monoclonal antibody 9A6 does, however, illustrate that this receptor also co-localizes with bound $\mathrm{Opa}_{52}$-expressing gonococci (data not shown), suggesting that CD66c is recruited during binding. Together with the complete abrogation of Opa-mediated transmigration by the competitive inhibition of binding by CD66-specific antibodies (Fig. 2D), these data directly implicate CD66 receptors as the mediators of these phenomena. Although microvilli are not typical of most tissues infected by the pathogenic Neisseriae, colorectal tissues of approximately $40 \%$ of women with uncomplicated gonorrhoea become colonized because of contamination from infected vaginal secretions (Handsfield, 1990; Knapp and Rice, 1995). The expression of CD66 receptors on the epithelium of the cervix and uterus (Prall et al., 1996) suggests that cellular transmigration, as described here, may also contribute to gonococcal dissemination from these sites.

The Opa ${ }_{50}$ protein has been described previously as the only gonococcal Opa that mediates the efficient invasion of cells grown into semi-confluent cultures in vitro (Makino et al., 1991; Kupsch et al., 1993; Chen et al., 1995a; van Putten and Paul, 1995). This observation is explained by the fact that transformed epithelial cell lines do not usually synthesize any CD66 receptors. Our results presented here, however, clearly show that gonococci expressing the HSPG-specific Opa ${ }_{50}$, or its chromosomally encoded $\mathrm{Opa}_{30}$ homologue, do not bind to or traverse the polarized T84 cells (Figs 1A, 2 and 6A). This finding is consistent with the fact that the HSPG-containing syndecan receptors that are recognized by $\mathrm{Opa}_{50}$ are expressed exclusively at the basolateral surface of polarized cells (Carey, 1997). Previous studies have reported a thinning of multilayered tissue and organ cultures and detachment of epithelial cells from the urethral lumen during neisserial infection (Stephens and Farley, 1991; Apicella et al., 1996; Mosleh et al., 1997). Such a breakdown of the polarized arrangement of a mucosal barrier would allow access to otherwise basolaterally localized receptors, thus suggesting that pilus-mediated binding to the apical surface would be a prerequisite for $\mathrm{Opa}_{50}$-mediated invasion.

Interestingly, confocal laser scanning microscopic analysis of T84 monolayers in the $x-z$ plane illustrated that CD66 proteins are expressed predominantly on the apical surface (Fig. 4E-H). This organization of neisserial receptors supports the premise that distinct adhesins of the gonococcal repertoire contribute to tissue interactions at different stages of the infectious process. Pilus is necessary for primary colonization of the male urethra in human infections (Seifert et al., 1994) and also mediates gonococcal binding to the apical surface of polarized cells in vitro (Fig. 1C; Merz et al., 1996; Pujol et al., 1997), suggesting that the initial adherence to mucosal epithelial tissues may be mediated by pilus. Subsequent tight association at the apical surface may occur via the CD66 
receptor-specific Opa proteins, leading to the engulfment and transcellular migration of gonococci across the intact polarized barrier. Colonization of the basolateral surface may then be mediated by the HSPG-specific Opa protein either via the cellularly expressed syndecan receptors (Chen et al., 1995; van Putten and Paul, 1995) or after anchorage to the extracellular matrix via vitronectin (Duensing and van Putten, 1997; Gomez-Duarte et al., 1997). Ligation of syndecan and the $\alpha_{v}$ integrin-containing vitronectin receptor can enhance the uptake of Opa ${ }_{50}$-expressing gonococci into epithelial cells (Dehio et al., 1998). It is intriguing to speculate that this provides a mechanism by which the gonococci can recolonize the apical surface, thereby continually reseeding the urethral lumen to make transmission to a new host possible. This model is consistent with the fact that there is a period after gonococcal inoculation during which bacteria cannot be recovered, while after this time, they return to levels seen at inoculation (Schneider et al., 1995). Adherence to CD66 receptors expressed on granulocytes (Chen and Gotschlich, 1996; Virji et al., 1996; Gray-Owen et al., 1997a) and activated endothelial cells (Gray-Owen et al., 1997b) may also contribute to interactions that occur during an inflammatory response to neisserial infection and during disseminated disease respectively.

\section{Experimental procedures}

\section{Bacterial strains and cell lines}

Recombinant neisserial (N302-N313; for further details, see Fig. 2) and E. coli (H1887, H1888, H1902-H1911; for further details, see Fig. 2) strains expressing the 11 genetically defined Opa proteins from N. gonorrhoeae MS11 were constructed by Kupsch et al. (1993). N. gonorrhoeae MS11-B2.1 strain N483 $\left(\mathrm{P}^{-} \mathrm{Opa}_{30}\right.$; Makino et al., 1991) and MS11-F3 strain N496 $\left(\mathrm{P}^{+} \mathrm{Opa}^{-}\right.$; Haas et al., 1987) have also been described previously. $\mathrm{N} 280\left(\mathrm{P}^{+} \mathrm{Opa}^{-}\right)$is a derivative of MS11-F3 carrying a chromosomal mutation of the $o_{0 a} C_{30}$ locus. N541 and N547 are derivatives of $\mathrm{N} 280$ expressing recombinant $\mathrm{Opa}_{50}$ and $\mathrm{Opa}_{52}$ respectively.

The culture of T84 cells was essentially as described previously (Dharmsathaphorn and Madara, 1990; Madara et al., 1992; Merz et al., 1996). T84 cells from the American Type Culture Collection (kindly provided by Dr Paul Hofman, Nice, France) were grown between passages 46 and 52 in T84 medium, a 1:1 mix of Dulbecco's modified Eagle medium (DMEM) and Ham's F-12 medium (Life Technologies) supplemented with $15 \mathrm{mM}$ HEPES buffer (pH7.4), $14 \mathrm{mM} \mathrm{NaHCO}_{3}$ and $6 \%$ heat-inactivated fetal calf serum $\left(56^{\circ} \mathrm{C}\right.$ for $30 \mathrm{~min}$; PAA Laboratories). Cells recovered from frozen stocks were cultured in T84 medium to a confluency of $70-80 \%$ before seeding for subsequent experiments. For adherence and traversal assays, harvested cells were seeded in $100 \mu$ l of T84 medium containing $4 \times 10^{4}$ cells onto collagen I (Collaborative Biotech)-coated Transwell filters $\left(3421 ; 0.33 \mathrm{~cm}^{2}\right.$ suspended polycarbonate filters; Costar), and $500 \mu$ l of T84 medium was added in the lower reservoir. For immunoblot and RT-PCR assays, harvested cells were seeded in $500 \mu$ l containing $2 \times 10^{5}$ cells onto collagen I-coated Transwell filters (3414; $4.7 \mathrm{~cm}^{2}$ suspended polycarbonate filters; Costar), and $2 \mathrm{ml}$ of T84 medium was added to the lower reservoir. Growth medium was changed daily, and the confluence and integrity of monolayers were assessed by measuring transepithelial electrical resistance (TEER) using a dual-voltage Ohmmeter clamp (Millicell-ERS; Millipore) inserted into the upper and lower reservoirs simultaneously (Perdomo et al., 1994). The TEER of most filters used for infection experiments typically exceeded $700 \Omega \mathrm{cm}^{2}$ per 3421 filter and $800 \Omega \mathrm{cm}^{2}$ per 3414 filter within 6-10 days after cell seeding.

\section{Immunoblot and RT-PCR analysis of CD66 receptor expression}

After washing with phosphate-buffered saline (PBS), all liquid was removed from the apical wells of uninfected T84 monolayer grown on 3414 Transwell filters, and total protein and RNA were extracted using TRIzol reagent (Life Technologies) according to the manufacturer's protocol. Mouse monoclonal antibody D14HD11, cross-reactive against CD66a, CD66c, CD66d and CD66e, and the CD66c-specific 9A6 used for immunoblot analysis of T84 cells were generously provided by Dr Fritz Grunert (University of Freiburg, Germany). Blots were developed after incubation with a peroxidase-conjugated goat anti-mouse lgG (Bio-Rad) using the ECL enhanced chemiluminescence substrate (Amersham).

Preparation of cDNA and subsequent PCR were performed as described previously (Thompson et al., 1993; Naumann et al., 1997). Primer sets used in this study are listed in Table 1. CD66 receptor-specific primers were used at 20-40 pmol per reaction, with $0.5-1$ pmol of GAPDH primers also included as an internal control in each reaction.

\section{Bacterial infection and transmigration assays}

Polarized T84 monolayers grown on 3421 Transwell filters and displaying a TEER of more than $700 \Omega \mathrm{cm}^{2}$ were rinsed with T84 medium and placed in fresh 24 -well plates containing $0.5 \mathrm{ml}$ of T84 medium. Aliquots of $100 \mu \mathrm{l}$ of medium containing either $2 \times 10^{6} \mathrm{~N}$. gonorrhoeae or $1 \times 10^{6} \mathrm{E}$. coli and indicated supplements were carefully added to the upper reservoir. Infected cells were incubated at $37^{\circ} \mathrm{C}$ with $5 \% \mathrm{CO}_{2}$. One half of the medium in the apical reservoir was replaced at 4-h (gonococcal infections) or 2-h (E. coli infections) intervals, and the medium in the lower (basolateral) reservoir was also changed by moving the filters to a new well containing fresh T84 medium. Dilutions of medium recovered from the basal reservoir were plated onto GC agar and incubated overnight at $37^{\circ} \mathrm{C}$ with $5 \% \mathrm{CO}_{2}$ in order to quantify bacterial transmigration (expressed as colony-forming units, cfu). Each strain was assayed in three to seven independent experiments with two to eight filters per strain per assay, unless otherwise stated. At the end of the assay ( $24 \mathrm{~h}$ after infection), each filter was assayed for TEER to verify that the barrier function had remained intact $\left(>700 \Omega \mathrm{cm}^{-2}\right)$.

For antibody inhibition assays, polyclonal antiserum reactive against CD66a, CD66c, CD66d and CD66e (anti-CEA; Dako) was added to obtain a final concentration of $100 \mu \mathrm{g}$

(C) 1998 Blackwell Science Ltd, Molecular Microbiology, 30, 657-671 
$\mathrm{ml}^{-1}$ in the culture medium of the upper reservoir. Before use, the azide-containing antibody storage buffer was replaced by T84 medium without FCS using a Centricon-30 concentrator (Amicon), as outlined by the manufacturer. The lack of this antibody's reactivity with $N$. gonorrhoeae was confirmed by direct immunofluorescence staining to assure that the effects seen resulted from its binding to CD66 receptors directly (data not shown).

For killing extracellular bacteria, gentamicin $\left(100 \mu \mathrm{g} \mathrm{ml}^{-1}\right)$ was added to both reservoirs for $2 \mathrm{~h}$. Protected intracellular bacteria were released by washing the filters three times in medium without gentamicin and lysis of the monolayer in $1 \%$ saponin/PBS for $15 \mathrm{~min}$, followed by rigorous pipetting of the liquid up and down to break cellular clusters further. cfu were determined by plating dilutions on GC agar. The time required by traversing bacteria for initial internalization into the monolayer was determined by adding gentamicin $\left(100 \mu \mathrm{g} \mathrm{ml}^{-1}\right)$ for $2 \mathrm{~h}$ only to the apical reservoir and then allowing the infection to continue in the continuous presence of a lower concentration of gentamicin $\left(20 \mu \mathrm{g} \mathrm{m}^{-1}\right)$ in the upper reservoir. The number of cfu appearing in the lower reservoir was determined as described above.

\section{Immunofluorescence staining and confocal laser scanning}

After infection, filters were washed three times with T84 medium for $5 \mathrm{~min}$ and then fixed using $3.7 \%(\mathrm{w} / \mathrm{v})$ paraformaldehyde (PFA) at room temperature for $20 \mathrm{~min}$. Filters were submerged in PFA and stored at $4^{\circ} \mathrm{C}$ until further use. Immunofluorescence staining was based on the method described previously (Dehio et al., 1997). PFA-fixed filters were washed three times in PBS for $5 \mathrm{~min}$ before and after each incubation step. To stain intracellular bacteria, fixed cells were incubated with $0.1 \%$ Triton X-100 $(\mathrm{v} / \mathrm{v})$ in PBS for $1 \mathrm{~h}$, followed by $0.2 \%$ BSA (w/v) in PBS for $10 \mathrm{~min}$ to block non-specific binding. Fixed monolayers were incubated sequentially with rat anti- $N$. gonorrhoeae MS11 B2.1 antiserum (AK231; diluted 1:300 in the blocking buffer), and then either Cy5-conjugated goat anti-rat IgG conjugate or Cy3-conjugated goat anti-rat IgG antibody (diluted 1:100 in blocking buffer), as indicated. Antibody conjugates were both from Jackson ImmunoResearch. For triple stainings, this was followed by either the CD66 cross-specific monoclonal antibody D14HD11 (diluted 1:400 in blocking buffer), CD66c-specific 9A6 (diluted 1:200 in blocking buffer) or rabbit anti-ZO-1 antibody (diluted 1:75 in blocking buffer; ADE Laborbedarf), as indicated, and then a mixture of either lissamine rhodamine (LRSC)-conjugated goat anti-mouse $\operatorname{lgG}(\mathrm{H}+\mathrm{L}$; diluted 1:100 in blocking buffer) or Cy5-conjugated goat anti-rabbit antibody, as indicated, and fluorescein isothiocyanate (FITC)-phalloidin (1:25 in blocking buffer; Sigma). All incubation steps were performed for $1 \mathrm{~h}$. After staining, filters were cut out of their Transwell supports and then mounted apical side up under coverslips in $100 \mathrm{mM}$ Tris- $\mathrm{HCl}, \mathrm{pH} 8.5,25 \%$ glycerol $(\mathrm{w} / \mathrm{v})$ and $10 \%$ Moviol 4-88 (w/v; Hoechst) for $30 \mathrm{~min}$. The specimens were sealed using nail polish and then stored at $4^{\circ} \mathrm{C}$ until analysis using a Leica TCS NT confocal laser scanning microscope (Leica Lasertechnik) equipped with an argonkrypton mixed gas laser. In triple stainings, the three channels were recorded simultaneously. Corresponding images were processed digitally using Photoshop 4.0 (Adobe Systems).

\section{Electron microscopy (SEM and TEM)}

After infection, filters were washed three times for $5 \mathrm{~min}$ with T84 medium without FCS, fixed with $2 \%$ glutaraldehyde (GA) in 0.2 M HEPES, $\mathrm{pH} 7.4$, at room temperature for $20 \mathrm{~min}$, and then submerged in $\mathrm{GA}$ at $4^{\circ} \mathrm{C}$ for storage. Electron microscopy was performed essentially as described previously (Dehio et al., 1997; Mosleh et al., 1997). Briefly, GAfixed filters were immersed in $1 \%$ osmium tetroxide in PBS $\left(\mathrm{OsO}_{4}\right.$; Science Services) for $2 \mathrm{~h}$, dehydrated in ethanol and critical point dried using liquid $\mathrm{CO}_{2}$. The filters were cut out of their Transwell supports, and the apical side was sputter coated with $1 \mathrm{~nm}$ chromium. The samples were then examined with a $10 \mathrm{kV}$ accelerating voltage using a Hitachi S-800 field emission scanning electron microscope equipped with a detector for back-scattered electrons (BSEs) of the YAG type. Photographs were taken using Agfa APX25 film (AgfaGevaert). For transmission electron microscopy (TEM), GAfixed filters were immersed in $1 \% \mathrm{OsO}_{4}$ for $1 \mathrm{~h}$ and, after dehydration through a graded series of ethanols, ultrathin sections were stained using $1 \%$ aqueous uranyl acetate and lead citrate. Stained filters were cut out, laid apical side up and then embedded in Epon. Samples were cut with a Diatome diamond knife (Reicher-Jung) using an ultramicrotome (LKB) and viewed using a Philips CM10 electron microscope. TEM micrographs were printed on Agfa Scientia film (Agfa-Gevaert).

\section{Acknowledgements}

We would like to thank Dr Paul Hofman (Nice, France) for providing T84 cells and for advice in culturing this cell line. We are grateful to Dr Fritz Grunert (Freiburg, Germany) for providing valuable antibodies, and to Dr Michael Naumann for help in establishing RT-PCR analysis. We also thank Bozena Pichler-Brand and Jürgen Berger for their excellent assistance in electron microscopy. This work was supported by DFG grant MC705/5-1.

\section{References}

Apicella, M.A., Ketterer, M., Lee, F.K.N., Zhou, D., Rice, P.A., and Blake, M.S. (1996) The pathogenesis of gonococcal urethritis in men: confocal and immunoelectron microscopic analysis of urethral exudates from men infected with Neisseria gonorrhoeae. J Infect Dis 173: 636-646.

Barnett, T.R., Drake, L., and Plautz, J.D. (1993) Human biliary glycoprotein gene: characterization of a family of novel alternatively spliced RNAs and their expressed proteins. Mol Cell Biol 13: 1273-1282.

Berling, B., Kolbinger, F., Grunert, F., Thompson, J.A., Brombacher, F., Buchegger, F., et al. (1990) Cloning of a carcinoembryonic antigen gene family member expressed in leukocyte of chronic myeloid leukemia patients and bone marrow. Cancer Res 50: 6534-6539.

Bos, M.P., Grunert, F., and Belland, R.J. (1997) Differential recognition of members of the carcinoembryonic antigen family by Opa variants of Neisseria gonorrhoeae. Infect Immun 65: 2353-2361.

Boxberger, H.J., Meyer, T.F., Grausam, M.C., Reich, K., Becker, H.D., and Sessler, M.J. (1994) Isolating and maintaining highly polarized primary epithelial cells from normal 
human duodenum for growth as spheroid-like vesicles. In Vitro Cell Dev Biol Animal 33: 536-545.

Canil, C., Rosenshine, I., Ruschkowski, S., Donnenberg, M.S., Kaper, J.B., and Finlay, B.B. (1993) Enteropathogenic Escherichia coli decreases the transepithelial electrical resistance of polarized epithelial monolayers. Infect Immun 61: 2755-2762.

Carey, D.J. (1997) Syndecans: multifunctional cell-surface co-receptors. Biochem J 327: 1-16.

Chen, J.C., Bavoil, P., and Clark, V.L. (1991) Enhancement of the invasive ability of Neisseria gonorrhoeae by contact with HeclB, an adenocarcinoma endometrial cell line. Mol Microbiol 5: 1531-1538.

Chen, T., and Gotschlich, E.C. (1996) CGM1a antigen of neutrophils, a receptor of gonococcal opacity proteins. Proc Natl Acad Sci USA 93: 14851-14856.

Chen, T., Belland, R., Wilson, J., and Swanson, J. (1995) Adherence of pilus ${ }^{-} \mathrm{Opa}^{+}$gonococci to epithelial cells in vitro involves heparan sulfate. J Exp Med 182: 511-517.

Chen, T., Grunert, F., Medina-Marino, A., and Gotschlich, E.C. (1997) Several carcinoembryonic antigens (CD66) serve as receptors for gonococcal opacity proteins. J Exp Med 185: 1557-1564.

Corthesy-Theulaz, I., Porta, N., Pringault, E., Racine, L., Bogdanova, A., Kraehenbuhl, J.P., et al. (1996) Adhesion of Helicobacter pylori to polarized T84 human intestinal cell monolayers is $\mathrm{pH}$ dependent. Infect Immun 64: 38273832.

Dehio, C., Meyer, M., Berger, J., Schwarz, H., and Lanz, C. (1997) Interaction of Bartonella henselae with endothelial cells results in bacterial aggregation on the cell surface and the subsequent engulfment and internalisation of the bacterial aggregate by a unique structure, the invasome. J Cell Sci 110: 2141-2154.

Dehio, M., Gomez-Duarte, O.G., Dehio, C., and Meyer, T.F. (1998) Vitronectin-dependent invasion of epithelial cells by Neisseria gonorrhoeae involves $\alpha \mathrm{v}$ integrin receptors. FEBS Lett 424: 84-88.

Dharmsathaphorn, K., and Madara, J.L. (1990) Established intestinal cell lines as model systems for electrolyte transport studies. Methods Enzymol 192: 354-389.

Duensing, T.D., and van Putten, J.P. (1997) Vitronectin mediates internalisation of Neisseria gonorrhoeae by Chinese hamster ovary cells. Infect Immun 65: 964-970.

Gabastou, J.M., Kerneis, S., Bernet-Camard, M.F., Barbat, A., Coconnier, M.H., Kaper, J.B., et al. (1995) Two stages of enteropathogenic Escherichia coli intestinal pathogenicity are up and down-regulated by the epithelial cell differentiation. Differentiation 59: 127-134.

Gomez-Duarte, O.G., Dehio, M., Guzman, C.A., Chhatwal, G.S., Dehio, C., and Meyer, T.F. (1997) Binding of vitronectin to opa-expressing Neisseria gonorrhoeae mediates invasion of HeLa cells. Infect Immun 65: 3857-3866.

Gray-Owen, S.D., Dehio, C., Haude, A., Grunert, F., and Meyer, T.F. (1997a) CD66 carcinoembryonic antigens mediate interactions between Opa-expressing Neisseria gonorrhoeae and human polymorphonuclear phagocytes. EMBO J 16: 3435-3445.

Gray-Owen, S.D., Lorenzen, D.R., Haude, A., Meyer, T.F., and Dehio, C. (1997b) Differential Opa specificities for CD66 receptors influence tissue interactions and cellular response to Neisseria gonorrhoeae. Mol Microbiol 26: 971-980.

Haas, R., Schwarz, H., and Meyer, T.F. (1987) Release of soluble pilin antigen coupled with gene conversion in Neisseria gonorrhoeae. Proc Natl Acad Sci USA 84: 90799083.

Handsfield, H.H. (1990) Neisseria gonorrhoeae. In Principles and Practice of Infectious Diseases. Mandell, G.L., Douglas, R.G., and Bennett, J.E. (eds). London: Churchill Livingstone, pp. 1613-1631.

Jepson, M.A., Collares-Buzato, C.B., Clark, M.A., Hirst, B.H., and Simmons, N.L. (1995) Rapid disruption of epithelial barrier function by Salmonella typhimurium is associated with structural modification of intercellular junctions. Infect Immun 63: 356-359.

Knapp, J.S., and Rice, R.J. (1995) Neisseria and Branhamella. In Manual of Clinical Microbiology. Murray, P.R., Baron, E.J., Pfaller, M.A., Tenover, F.C. and Yolken, R.H. (eds). Washington, D.C: American Society for Microbiology Press, pp. 324-340.

Kupsch, E.-M., Knepper, B., Kuroki, T., Heuer, I., and Meyer, T.F. (1993) Variable opacity (Opa) outer membrane proteins account for the cell tropisms displayed by Neisseria gonorrhoeae for human leukocytes and epithelial cells. EMBO J 12: 641-650.

McCormick, B.A., Colgan, S.P., Delp-Archer, C., Miller, S.I., and Madara, J.L. (1993) Salmonella typhimurium attachment to human intestinal epithelial monolayers: transcellular signalling to subepithelial neutrophils. J Cell Biol 123: 895-907.

McCormick, B.A., Hofman, P.M., Kim, J., Carnes, D.K., Miller, S.I., and Madara, J.L. (1995) Surface attachment of Salmonella typhimurium to intestinal epithelia imprints the subepithelial matrix with gradients chemotactic for neutrophils. J Cell Biol 131: 1599-1608.

McGee, Z.A., Johnson, A.P., and Taylor-Robinson, D. (1981) Pathogenic mechanisms of Neisseria gonorrhoeae: observations on damage to human fallopian tubes in organ culture by gonococci of colony type 1 or type 4 . J Infect Dis 143: 413-422.

McGee, Z.A., Stephens, D.S., Hoffman, L.H., Schlech, W.F., and Horn, R.G. (1983) Mechanisms of mucosal invasion by pathogenic Neisseria. Rev Infect Dis 5(suppl.): 708-714.

McRoberts, J.A., and Barrett, K.E. (1989). Hormone-regulated ion transport in T84 colonic cells. In Functional Epithelial Cells in Culture. Matlin, K.S., and Valentich, J.D. (eds). New York: Alan R. Liss, pp. 235-265.

Madara, J.L. (1988) Tight junction dynamics: is paracellular transport regulated? Cell 53: 497-498.

Madara, J.L., Colgan, S.P., Nusrat, A., Delp, C., and Parkos, C.A. (1992) A simple approach to measurement of electrical parameters of cultured epithelial monolayers: use in assessing neutrophil epithelial interactions. Tissue Cult Res 14: 209-216.

Majuri, M.-L., Hakkarainen, M., Paavonen, T., and Renkonen, R. (1994) Carcinoembryonic antigen is expressed on endothelial cells. APMIS 102: 432-438.

Makino, S.I., van Putten, J., and Meyer, T.F. (1991) Phase variation of the opacity outer membrane protein controls invasion by Neisseria gonorrhoeae into human epithelial cells. EMBO J 10: 1307-1315. 
Merz, A.J., Rifenbery, D.B., Arvidson, C.G., and So, M. (1996) Traversal of a polarized epithelium by pathogenic Neisseriae: facilitation by type IV pili and maintenance of epithelial barrier function. Mol Med 2: 745-754.

Mosleh, I.M., Boxberger, H.J., Sessler, M.J., and Meyer, T.F. (1997) Experimental infection of native human ureteral tissue with Neisseria gonorrhoeae: adhesion, invasion, intracellular fate, exocytosis, and passage through a stratified epithelium. Infect Immun 65: 3391-3398.

Murakami, H., and Masui, H. (1980) Hormonal control of human colon carcinoma cell growth in serum-free medium. Proc Natl Acad Sci USA 77: 3464-3468.

Nataro, J.P., Hicks, S., Phillips, A.D., Vial, P.A., and Sears, C.L. (1996) T84 cells in culture as a model for enteroaggregative Escherichia coli pathogenesis. Infect Immun 64: 4761-4768.

Naumann, M., Wessler, S., Bartsch, C., Wieland, B., and Meyer, T.F. (1997) Neisseria gonorrhoeae epithelial cell interaction leads to the activation of the transcription factors NF-kB and AP1 and the induction of inflammatory cytokines. J Exp Med 186: 247-258.

Perdomo, J.J., Gounon, P., and Sansonetti, P.J. (1994) Polymorphonuclear leukocyte transmigration promotes invasion of colonic epithelial monolayer by Shigella flexneri. $J$ Clin Invest 93: 633-643.

Philpott, D.J., McKay, D.M., Sherman, P.M., and Perdue, M.H. (1996) Infection of T84 cells with enteropathogenic Escherichia coli alters barrier and transport functions. Am J Physiol 270: 634-645.

Prall, F., Nollau, P., Neumaier, M., Haubeck, H.-D., Drzeniek, Z., Helmchen, U., et al. (1996) CD66a (BGP), an adhesion molecule of the carcinoembryonic antigen family, is expressed in epithelium, endothelium, and myeloid cells in a wide range of normal human tissues. $J$ Histochem Cytochem 44: 35-41.

Pujol, C., Eugene, E., de Saint, M., and Nassif, X. (1997) Interaction of Neisseria meningitidis with a polarized monolayer of epithelial cells. Infect Immun 65: 4836-4842.

van Putten, J.P.M., and Duensing, T.D. (1997) Infection of mucosal epithelial cells by Neisseria gonorrhoeae. Rev Med Microbiol 8: 51-59.

van Putten, J.P.M., and Paul, S.M. (1995) Binding of syndecan-like cell surface proteoglycan receptors is required for Neisseria gonorrhoeae entry into human mucosal cells. EMBO J 14: 2144-2154.

van Putten, J.P.M., Duensing, T.D., and Cole, R.L. (1998) Entry of $\mathrm{OpaA}^{+}$gonococci into HEp-2 cells requires concerted action of glycosaminoglycans, fibronectin and integrin receptors. Mol Microbiol 29: 369-379.

Rudel, T., van Putten, J.P.M., Gibbs, C.P., Haas, R., and
Meyer, T.F. (1992) Interaction of two variable proteins (PilE and PilC) required for pilus-mediated adherence of Neisseria gonorrhoeae to human epithelial cells. Mol Microbiol 6: 3439-3450.

Schneider, H., Cross, A.S., Kuschner, R.A., Taylor, D.N., Sadoff, J.C., Boslego, J.W., et al. (1995) Experimental human gonococcal urethritis: 250 Neisseria gonorrhoeae MS11mkC are infective. J Infect Dis 172: 180-185.

Seifert, H.S., Wright, C.J., Jerse, A.E., Cohen, M.S., and Cannon, J.G. (1994) Multiple gonococcal pilin antigenic variants are produced during experimental human infections. J Clin Invest 93: 2744-2749.

Shaw, J.H., and Falkow, S. (1988) Model for invasion of human tissue culture cells by Neisseria gonorrhoeae. Infect Immun 56: 1625-1632.

Silverstein, S.C., Steinman, R.M., and Cohn, Z.A. (1977) Endocytosis. Annu Rev Biochem 46: 669-722.

Stephens, D.S., and Farley, M.M. (1991) Pathogenic events during infection of the human nasopharynx with Neisseria meningitidis and Haemophilus influenzae. Rev Infect Dis 13: 22-33.

Stephens, D.S., Hoffman, L.H., and McGee, Z.A. (1983) Interaction of Neisseria meningitidis with human nasopharyngeal mucosa: attachment and entry into columnar epithelial cells. $J$ Infect Dis 148: 369-376.

Thompson, J.A., Grunert, F., and Zimmerman, W. (1991) Carcinoembryonic antigen gene family: molecular biology and clinical perspectives. J Clin Lab Anal 5: 344-366.

Thompson, J., Mossinger, S., Reichardt, V., Engels, U., Beauchemin, N., Kommoss, F., et al. (1993) A polymerasechain-reaction assay for the specific identification of transcripts encoded by individual carcinoembryonic antigen (CEA)-gene-family members. Int J Cancer 55: 311-319.

Virji, M., Makepeace, K., Ferguson, D.J.P., and Watt, S. (1996) Carcinoembryonic antigens (CD66) on epithelial cells and neutrophils are receptors for Opa proteins of pathogenic Neisseriae. Mol Microbiol 22: 941-950.

Wallis, T.S., Starkey, W.G., Stephen, J., Haddon, S.J., Osborne, M.P., and Candy, D.C. (1986) The nature and role of mucosal damage in relation to Salmonella typhimurium-induced fluid secretion in the rabbit ileum. $J$ Med Microbiol 22: 39-49.

Winsor, D.K.J., Ashkenazi, S., Chiovetti, R., and Cleary, T.G. (1992) Adherence of enterohemorrhagic Escherichia coli strains to a human colonic epithelial cell line (T84). Infect Immun 60: 1613-1617.

Wong, H., Anderson, W.D., Cheng, T., and Riabowol, K.T. (1994) Monitoring mRNA expression by polymerase chain reaction: the 'primer-dropping' method. Anal Biochem 223: $251-258$. 